\title{
Oil discoveries and political windfalls: Evidence on presidential support in Uganda
}

\author{
Laura Paler, ${ }^{1}$ Jeremy Springman, ${ }^{2}$ Guy Grossman, ${ }^{3}$ and Jan Pierskalla ${ }^{4}$ \\ ${ }^{1}$ Department of Government, School of Public Affairs, American University, Washington, DC, USA \\ ${ }^{2}$ DevLab@Penn, University of Pennsylvania, Philadelphia, PA, USA \\ ${ }^{3}$ Department of Political Science, University of Pennsylvania, Philadelphia, PA, USA \\ ${ }^{4}$ Department of Political Science, Ohio State University, Columbus, OH, USA \\ (Received 12/14/2021; revised 6/7/2021; accepted ; first published online )
}

\begin{abstract}
Oil discoveries, paired with delays in production, have created a new phenomenon: sustained postdiscovery, pre-production periods. While research on the resource curse has debated the effects of oil on governance and conflict, less is known about the political effects of oil discoveries absent production. Using comprehensive electoral data from Uganda and a difference-in-difference design with heterogeneous effects, we show that oil discoveries increased electoral support for the incumbent chief executive in localities proximate to discoveries, even prior to production. Moreover, the biggest effects occurred in localities that were historically most electorally competitive. Overall, we show that the political effects of oil discoveries vary subnationally depending on local political context and prior to production, with important implications for understanding the roots of the political and conflict curses.
\end{abstract}

Since the early 2000s, technological innovations in oil and gas extraction, coupled with recordlevel investments in natural resource exploration, have culminated in a number of 'giant' discoveries (Bhattacharyya, Conradie, and Arezki 2017). ${ }^{1}$ While some of these discoveries have taken place in long-time oil exporting countries like Angola and Nigeria, others have occurred in developing countries with no previous discoveries (Zhang et al. 2019). In sub-Saharan Africa alone, 12 countriesincluding Kenya, Ghana, Tanzania, and Uganda-have become prospective oil and gas exporters. Across these countries, the average expected annual gross value of resources discovered since 2001 (as a percentage of 2000 GDP) is 81 percent (Mihalyi and Scurfield 2020).

Interestingly, the average period between discovery and production in these countries is often lengthy—about 12 years on average in Sub-Saharan Africa-due to the technical and logistical challenges of extraction; protracted negotiations with investors and multinational oil companies; and the slow process of creating regulatory, legal, and institutional frameworks to govern the extractive

(C) Cambridge University Press 2021. This is an Open Access article, distributed under the terms of the Creative Commons Attribution licence (http://creativecommons.org/licenses/by/4.0/), which permits unrestricted re-use, distribution, and reproduction in any medium, provided the original work is properly cited.

1. Giant fields are those with at least 500 million barrels of recoverable reserves (Khan et al. 2016). 
sector (Mihalyi and Scurfield 2020). Increasingly, countries find themselves in prolonged postdiscovery, pre-production periods in which the presence of oil and gas reserves are known, expectations about future revenue flows and institutions for managing them are being formed, but little actual resource extraction is happening.

Large discoveries of oil and gas and sustained pre-production periods raise questions about how new resource endowments impact the political and economic trajectories of low-income countries before substantial revenues even begin to accrue (Frynas and Buur 2020). There is growing evidence that governments, firms, and citizens change their behavior in the pre-production period in anticipation of future earnings (Arezki, Ramey, and Sheng 2017; Cust and Mensah 2020). Yet, to date, the nascent 'pre-production' (or 'pre-source curse') literature has focused almost exclusively on economic outcomes (e.g. Harding, Stefanski, and Toews 2020). Few studies, if any, have analyzed the electoral consequences for incumbents of giant discoveries in the pre-production period.

Our study addresses this lacuna for two reasons. First, the pre-production period is an important period to understand in its own right. This is a pivotal time when the institutional framework governing the extractive sector is established (Langer, Ukiwo, and Mbabazi 2019; Lee and Dupuy 2018). Oil discoveries that increase incumbent support could mean less pressure to constrain leaders at a critical juncture, contributing to the kind of weak institutional environment or incumbency advantage associated with the political resource curse (Menaldo 2016; Mahdavi 2015). Alternatively, oil discoveries that decrease incumbent support could indicate the kind of emergent grievances linked to the conflict curse (Ross 2012). Ultimately, since developments during the pre-production period set the stage for what happens once production is underway, a better understanding of how citizens respond to oil discoveries offers deeper insight into the likelihood and roots of a political or a conflict curse than can be obtained by studying the production period alone.

Second, it is important to investigate empirically the electoral consequences of oil discoveries because existing theories provide unclear or contradictory predictions. While the vast literature on the political resource curse shows that resource windfalls strengthen autocratic rule, weaken accountability in democracies, and increase corruption and patronage, these outcomes depend on the existence of large rents that allow leaders to substitute for taxation, invest in repression, or buy political support (Beblawi and Luciani 1987; Aslaksen 2010; Robinson, Torvik, and Verdier 2006). In contrast, oil discoveries can be conceptualized as information shocks that reduce uncertainty about 
future production (Arezki, Ramey, and Sheng 2017), and it is unclear whether and how discoveries will impact incumbent support when they have not yet yielded the full level of rents. Electoral gains or losses in the pre-production period depend on how citizens and leaders interact over the benefits and costs of future production. Incumbents could enjoy increased support if their promises of future benefits are viewed as credible or if citizens use their vote to signal loyalty in the hopes of solidifying a clientelist exchange (Gottlieb et al. 2019). Conversely, oil discoveries could reduce support if promises are seen as not credible; benefits take too long or fail to materialize; or large pre-production costs (like forced dislocation) go uncompensated (Kiiza, Bategeka, and Ssewanyana 2011).

In light of the above, our main goal is to examine how giant oil discoveries affect within country variation in electoral support for an incumbent chief executive. We focus on chief executives because they hold disproportionate decision-making power over how oil rents are spent, especially in Africa (Omgba 2009). We focus on within country variation because citizen-leader interaction over the costs and benefits of future production—and consequently the scope for electoral gains or losses—is typically more intense in localities proximate to discoveries (Ahmad and Mottu 2003). Citizens living proximate to oil commonly express a stronger sense of ownership over the resource, expectations of greater benefits, and concerns about bearing the environmental and other costs associated with extraction (Ross 2012). Consequently, political (and fairness) considerations often motivate leaders to promise a greater share of the benefits to oil localities, even while promising benefits to the country as a whole (McClure 2003; Ahmad and Mottu 2003). ${ }^{2}$

We estimate the subnational effects of oil discoveries using highly granular data from Uganda. Uganda is a relevant case as a competitive authoritarian regime with a long-standing chief executive and an extended pre-production period. ${ }^{3}$ To identify the effect of an oil discovery, we must consider an appropriate counterfactual. While oil discovery locations depend in part on exogenous geographic and technological conditions (Lei and Michaels 2014), they also depend on exploration activities that themselves could be driven by economic, political, or other factors that also correlate with our

2. Legislation passed in 2015 indicated Uganda was also planning to give a greater share of the benefits to local governments in oil regions (Langer, Ukiwo, and Mbabazi 2019, p. 268), although the specifics of this arrangement were unresolved during the period under study.

3. While oil was discovered in Uganda in 2006, production is currently not expected until 2025 (World Bank 2020). While this is a long pre-production period, Uganda was within the 12-year average for Sub-Saharan Africa estimated by Mihalyi and Scurfield (2020) until 2018. Our main outcome data comes from 2011, at which time production was expected to begin later that year (Brock 2010). Thus, our main findings capture the effects of an anticipated 5 year pre-production period, which is consistent with the global average for onshore oil estimated in Arezki, Ramey, and Sheng (2017). 
outcome of interest. This implies that a simple comparison of localities with and without oil could be biased. Thus, we leverage features of Uganda's exploration history with a difference-in-differences design to isolate the impact of discoveries on the difference in changes in presidential support across localities more proximate to oil discoveries ('oil localities') compared to those that are more distant ('non-oil localities').

Our second goal is to explore whether the effects of discoveries on incumbent support vary not just by proximity to oil but also by the strength of localities' historical support for the incumbent chief executive. Historical support potentially plays a critical role in conditioning the effects of oil discoveries because of how it shapes citizen-leader interaction (including the credibility of promises) over the benefits and costs of future oil production. This follows from research on distributive politics, which shows how electoral responsiveness to distributive proposals—and consequently leaders' promises of targeted benefits—varies across 'core', 'swing', and 'opposition' localities (for literature reviews, see Stokes et al. 2013 and Golden and Min 2013.) This literature shows that promises of targeted benefits yield the biggest electoral gains in swing (and sometimes core) constituencies. Combined with the above incentives to promise more benefits to oil localities, this suggests the potential for the greatest electoral gains in swing (or core) constituencies with oil.

However, research on distributive politics in more authoritarian settings suggests that oil discoveries could also affect incumbent support in 'opposition' localities (see Golden and Min 2013, 81-82). Because oil increases the economic and political value to the incumbent of proximate localities, discoveries also strengthen leaders' incentives to promise benefits to oil-rich opposition localities to buy support or forestall unrest (Caselli and Cunningham 2009; Dal Bo and Powell 2009). While such promises could increase incumbent support in opposition localities if they are viewed as credible, the prevalence of information and commitment problems in such contexts suggest that efforts to secure support in opposition areas often fail (Dal Bo and Powell 2009; Paine 2019), potentially contributing to bigger relative losses in incumbent electoral support in oil versus non-oil opposition localities. All in all, it is important to examine how historical incumbent support moderates the effects of discoveries because some oil localities might bestow electoral gains and others losses, resulting in average effects that obscure important underlying variation. Exploring heterogeneity is also important to developing better theories of the subnational distributive politics of oil. In our analysis, we draw on the fact that Ugandan oil was discovered near stronghold, competitive, and opposition localities, allowing us to 
examine the heterogeneous effects of oil discoveries.

We find that oil discoveries in Uganda caused a small but meaningful increase in the president's electoral support on average. However, these modest average effects indeed obscure important variation: we find large increases in localities with intermediate levels of past support compared to far smaller increases in stronghold areas and decreases in opposition localities. This indicates that, even during the pre-production period, oil discoveries allowed the incumbent chief executive to make political gains in precisely those localities that have historically been more electorally competitive. Ultimately, this paper shows that oil discoveries can contribute to incumbency advantage even in advance of big changes to the country's revenue base; draws attention to the political importance of the pre-production period; and calls for more research into how and why distributive politics shape subnational variation in the electoral and political consequences of oil discoveries.

\section{Empirical Strategy}

Oil in commercial quantities was first discovered in Uganda in the Albertine Graben in June 2006 (see Figure 1). As a low-income country characterized by weak state capacity, weak electoral institutions, and a history of civil conflict, Uganda is at risk of a resource curse. Additionally, as in many African countries, Uganda has a long-time incumbent chief executive in President Yoweri Museveni, who has used his executive authority to assert control over the nascent oil sector (Langer, Ukiwo, and Mbabazi 2019). Uganda is, however, a competitive authoritarian regime with enough political competition to allow for meaningful shifts in electoral support (Tripp 2010).

Our main outcome of interest is the change in President Museveni's win margin between the February 2006 (pre-discovery) and 2011 (post-discovery) presidential elections, calculated as the vote share for Museveni minus the vote share of the closest runner-up. We focus on win margin because it is a function of both political support and changes in overall competitiveness, although we also obtain similar results when using vote share as the outcome of interest (see Appendices G-K). We compiled electoral data from the Uganda Electoral Commission and created the most comprehensive and detailed collection of parish-level election results across four elections in Uganda to date (see Appendix A for details). We use the parish—Uganda's lowest administrative unit above villages—as our unit of analysis because many salient public goods, such as primary schools and health clinics, operate at the parish-level, making it a highly relevant unit for considering the effect of expectations 


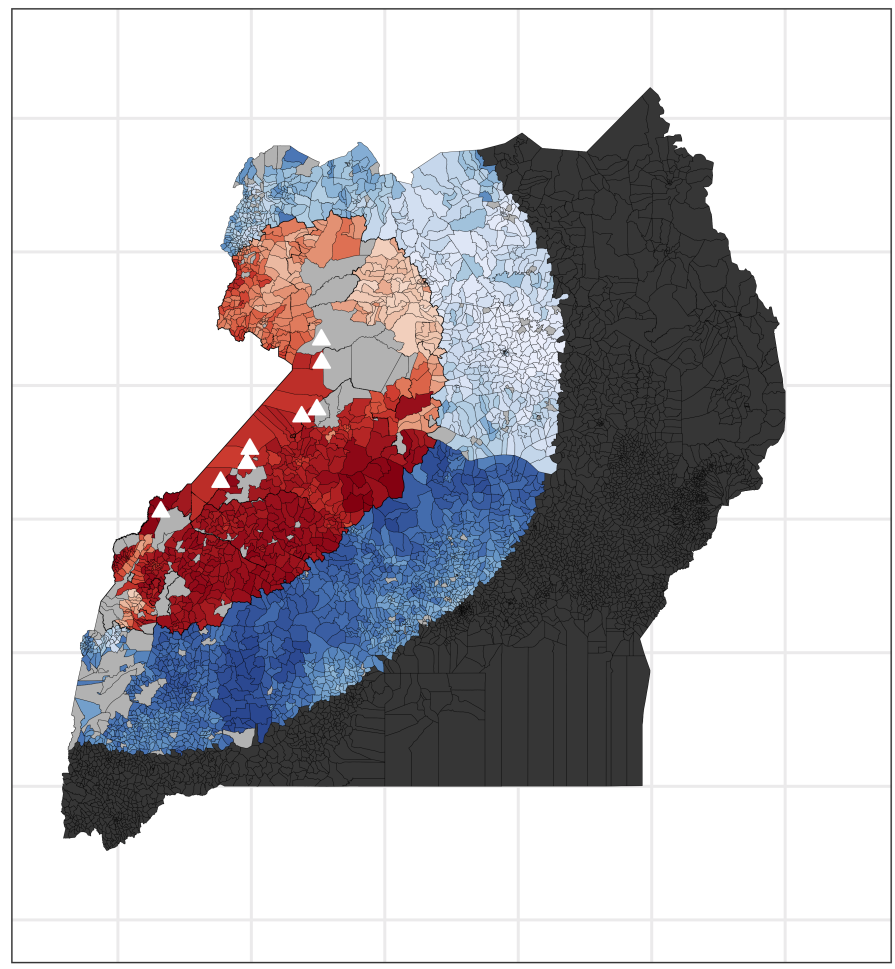

Vote Share $(0-100 \mathrm{~km})$

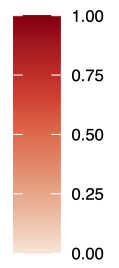

Vote Share $(100 \mathrm{~km}-200 \mathrm{~km})$

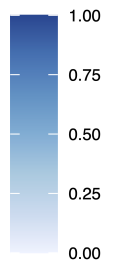

Figure 1. This figure shows the location of the oil discoveries (white triangles) and the location of oil parishes (red) versus non-oil parishes (blue) as defined by our binary measure. More intense shading, regardless of color, indicates stronger pre-discovery vote share for Museveni. Light grey polygons predominantly indicate uninhabited areas, including national parks near the discoveries, while dark grey parishes are excluded from the main analysis.

about future benefits.

Our key independent variable is based on localities' distance to one of Uganda's eight oil wells discovered in 2006-2007 (see Figure 1). For each of more than 5,000 parishes, we calculate the distance between a parish centroid and the geo-referenced location of the nearest oil discovery. For the binary independent variable, we define all parishes within 100 kilometers of a discovery as oil localities (the treatment group). Interviews and a thorough review of reports from the Ugandan media suggest that this is an appropriate treatment bandwidth when considering shocks to expectations about future benefits. In our main analysis, we define all parishes between 101 and $200 \mathrm{~km}$ as non-oil localities (the control group), although we check robustness to varying the composition of the control group to include only parishes within 101-150 kilometers of a discovery as well as to include all parishes in the country (see Appendices G and K). Additionally, we create continuous measures of proximity to a discovery, including the inverse of each parish's distance to the nearest well in 
$10 \mathrm{~km}$ units and an IHS-transformation that allows us to retain zero-valued observations and to interpret results in percentage terms (see Appendix G). The continuous measures allow us to better differentiate the effects of oil discoveries from those of oil exploration, as elaborated below.

We use difference-in-differences to capture changes in trajectories in presidential support in oil versus non-oil localities. This approach allows for estimating the causal effects of oil discoveries even when discoveries are not fully exogenous. This is important because oil discoveries are due not only to exogenous geographic and technological conditions but also to exploration activities, which can be endogenous to many factors also correlated with incumbent support. This raises the concern that estimates of the effects of oil discoveries could be biased by factors associated with selection into exploration (and subsequent discovery).

Our difference-in-differences design helps to address concerns about confounding due to endogenous exploration in three ways. First, it controls, by design, for time invariant confounders, including exposure to exploration. Beginning in the 1930s and up until the 2006 discoveries, exploration was widespread in the Albertine Graben such that all parishes in the discovery area had long-term exposure to exploration activities. Second, it flexibly controls for time-varying confounders that could drive differential changes in incumbent support in oil versus non-oil localities, as elaborated below. Third, it allows us to check for parallel trends (see below) and show that no divergence in incumbent support occurred prior to the 2006 discoveries, suggesting that selection into exploration is not biasing our results.

While these features of our differences-in-differences design help to mitigate concerns about confounding due to endogenous exploration and discovery, we note that this is not necessarily a major cause for concern in the Uganda case. Publicly available information shows that, prior to 2006, there had been exhaustive exploration attempts along the entire North-South length of the Albertine Graben (Nimmagadda et al. 2006). The thoroughness of exploration activity suggests that it was driven more by geographic conditions than by strategic considerations. Additionally, the 2006 discoveries were made possible by technological advances rather than by changes in the regime's approach to exploration. The fact that discoveries occurred in areas both historically aligned with and opposed to the president further suggests that exploration was not driven by political considerations that could bias our estimates.

We estimate a difference-in-differences regression of the following form: 


$$
\begin{aligned}
y_{i t} & =\eta_{i}+\gamma_{t}+\beta_{1}\left(\text { oil }_{i} \cdot \text { post }_{t}\right)+\beta_{2}\left(\text { post }_{t} \cdot \text { voteshare }_{i}\right) \\
& +\beta_{3}\left(\text { post }_{t} \cdot \text { voteshare }_{i}^{2}\right)+\beta_{4}\left(X_{i} \cdot \text { post }_{t}\right)+\epsilon_{i t}
\end{aligned}
$$

where $y_{i t}$ is Museveni's win margin in parish $i$ at time $t$. oil $i$ is either a dummy for oil localities or the continuous measure of proximity to the nearest discovery, post $t_{t}$ indicates the post-discovery period, and oil $_{i} \times$ post $_{t}$ is the difference-in-difference interaction term. We include parish and year fixed effects $\eta_{i}$ and $\gamma_{t}$ to account for both time invariant unobserved confounders and yearly shocks. ${ }^{4}$ Standard errors, $\epsilon_{i t}$, are clustered at the parish level.

As mentioned, our estimation strategy also addresses concerns that time varying factors could confound our estimates. First, we include linear and quadratic trends based on pre-treatment (2006) levels of presidential support, represented by the post $\cdot$ voteshare $_{i}$ and post $\cdot$ voteshare $_{i}^{2}$ terms. Second, we include parish-level controls drawn from pre-treatment election and census data, including voter turnout, a wealth index (see Appendix B), population size, share of population working in agriculture, and share of population that are co-ethnics with the president. We model all controls flexibly by interacting them with the binary post-discovery indicator to capture time-varying confounding effects of changes in the local economic and political environment (including the effect of exploration activity), denoted $X_{i} \cdot$ post $_{t}$. Given that it is not possible to conclusively rule out the influence of unobserved time-varying confounders, we also conduct a sensitivity analysis to quantify the amount of bias required to drive our estimates to zero. The results, available in Appendix L, demonstrate that confounding would need to have more explanatory power than the other strong historical trends that we control for.

To estimate the heterogeneous effects of oil discoveries, we expand the above to estimate a tripledifference model (see Appendix C). Following Hainmueller, Mummolo, and Xu (2019), we use a binning estimator to convert the continuous measure of presidential vote share into three categorical bins reflecting 'low', 'medium', and 'high' historical support. To estimate heterogeneous effects more flexibly, we also use kernel density estimation to obtain the marginal effect of oil discoveries across the full range of the moderator variable.

4. Fixed effects also control for proximity to exploration, which is time invariant in our sample. 
Unbiased inference in a difference-in-differences design requires the assumption that outcome trends would have proceeded in parallel in the absence of the treatment. Our empirical strategy allows us to inspect the identifying assumption that oil and non-oil localities would have exhibited parallel trends in incumbent support in the absence of oil discoveries. We use election data from 2001 and 2006 to provide evidence to support the parallel trends assumption, with results presented in Appendix D. In addition to showing visually that the parallel trends assumption holds, we test this more formally by estimating models that include both the 2001 and 2006 pre-treatment periods (see Appendix sections I and H). Importantly, these results also help to reassure that our findings are driven by oil discoveries rather than by factors that drove selection into exploration. Given that exploration was underway long before discoveries occurred and that discovery and exploration are correlated, differential effects on incumbent support in oil versus non-oil localities due to endogenous exploration should manifest as a violation of the parallel trends assumption prior to 2006.

While the discussion so far helps to allay concerns about bias due to confounding by factors that drive selection into exploration, one final concern might be that we are in fact confounding our treatments, meaning that we are mis-attributing the effects of oil exploration to oil discoveries. This is important because exploration activities also constitute powerful shocks that could affect incumbent support, for instance by creating expectations of future benefits or materially changing citizens' lives through land-grabbing, as was the case in Uganda (Bashir and Brophy 2015). Critically, effects due to exploration make it harder for us to detect discovery effects because they imply, for instance, less scope for learning or changes in expectations of future benefits.

Nevertheless, additional features of our estimation strategy and context help to reassure that we are capturing the effects of oil discovery rather than of oil exploration. First, by employing a continuous measure of proximity to oil discoveries in addition to the binary measure, we capture proximity to the precise location of discoveries, even among the sample of localities in the Albertine Graben region where exploration activities were widespread and could also influence incumbent support. This is further supported by additional analysis, reported in Appendix K, in which we restrict our sample to parishes more proximate to exploration activity (those within $150 \mathrm{~km}$ of an oil discovery). Second, there were no concurrent changes in exploration in 2006 that coincided with the discoveries, making it unlikely that the observed divergence after 2006 is due to exploration activities rather than the discoveries themselves. Our parallel trends results also provide reassurance insofar as any 
effects due to exploration rather than discovery should against have manifested as a divergence in incumbent support prior to 2006.

\section{Results}

We report two main findings. First, as shown in Table 1, we find that, on average, proximity to an oil discovery caused a small but meaningful increase in Museveni's margin of victory. Being within $100 \mathrm{~km}$ of the nearest oil discovery increased the president's win margin by between 1.3 and 2.2 percentage points (columns 1-2). We obtain similar results using our two continuous measures in columns 3-4 and 5-6. We find that a 10 kilometer (or 10 percent) increase in proximity yields between a 0.2 and 0.3 (0.15 and 0.23 ) percentage point increase in the relative win margin. These results are robust to the inclusion of parishes more $200 \mathrm{~km}$ from a discovery and of additional presidential elections (adding 2001 and/or 2016) (see Appendices G-J). These latter results, which show that oil discoveries allowed Museveni to strengthen his political power over at least ten years and two general election cycles, serve to reinforce the importance of the pre-production period.

Table 1. Effect of Oil Discovery on Presidential Win Margin (2006-2011)

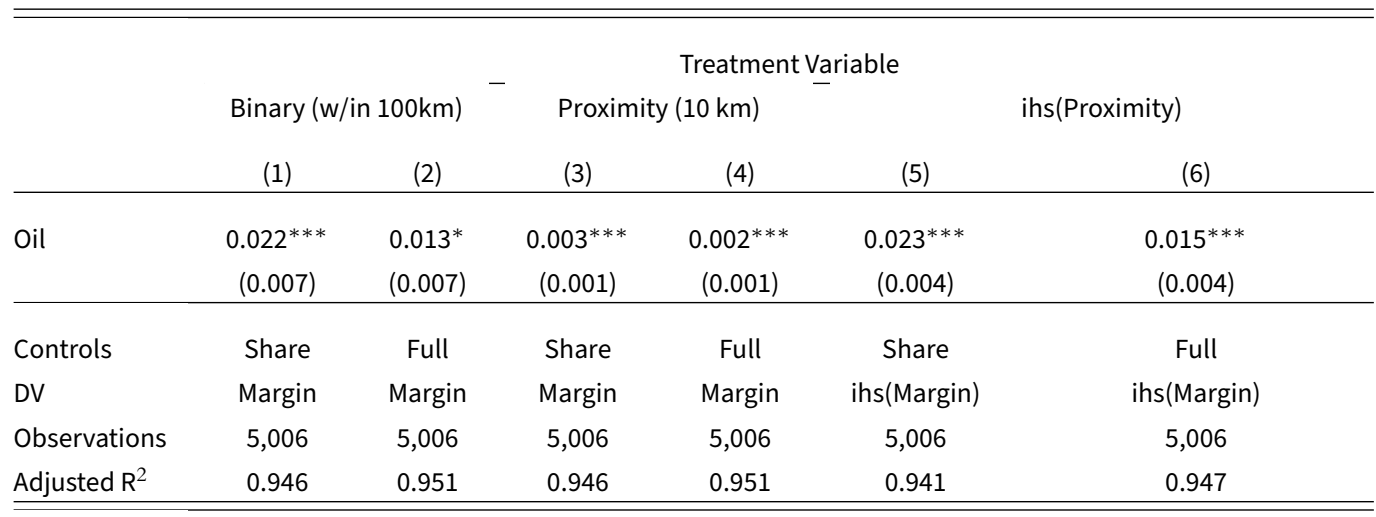

Notes: Sample includes parishes within $200 \mathrm{~km}$ of nearest oil discovery. Pre-treatment flexible controls include parish-level measurements of president's vote share and its square (labeled 'Share'), voter turnout, population, a wealth index, and the share of population employed in agriculture and coethnics with the president. ${ }^{*} p<0.1$; ${ }^{* *} \mathrm{p}<0.05 ;{ }^{* * *} \mathrm{p}<0.01$

Second, we find that the effects of proximity to an oil discovery vary substantially depending on a locality's historical level of incumbent support. Panel A of Figure 2 shows how the effects of proximity to an oil discovery vary across 'opposition', 'competitive, and 'stronghold' parishes (those with less than 40\%, 40-60\%, and greater than 60\% vote share for Museveni in the 2006 
presidential elections, respectively). The results reveal that the oil discoveries caused a substantial increase in electoral support for Museveni in precisely those localities that had previously been most electorally competitive. Smaller increases in stronghold localities were likely limited by ceiling effects while smaller decreases in opposition localities provide suggestive evidence of deepening antagonism towards the president. This pattern of findings is reinforced by the nonlinear marginal effects models reported in Panel B.

We examine a number of possible explanations for these results in Appendix E. While the mechanism evidence is suggestive, it indicates that oil discoveries affected the electoral and distributive bargains between voters and the incumbent president, to differential effect in stronghold, competitive, and opposition localities. It is most likely that the oil discoveries either induced Museveni to increase promises to voters in oil, especially competitive oil, localities or prompted voters in those localities to engage in 'strategic signalling'-preemptively voting for Museveni in 2011 in order to send a credible signal of willingness to reward future oil benefits (Gottlieb et al. 2019). This is consistent with Museveni's history of winning at the polls in part by exerting tight control over distributive benefits and by explicitly tying benefits to supplying political support (Lyatuu 2018). We find further support for such dynamics through an original analysis of newspaper articles, which shows that Museveni indeed made more campaign promises to oil localities (Appendix E.1). Additional analysis using Afrobarometer survey data, reported in Appendix E.2, shows a corresponding increase in expectations of future benefits among voters in those localities.

Importantly, changes in electoral support for Museveni appear to be driven entirely by interaction over future benefits; in Appendix E.3 we find no evidence of increases in actual spending or public goods provision in the pre-production period. We also rule out a number of alternative explanations in Appendix F, including that oil discoveries caused differential increases in electoral intimidation or migration that changed the political composition of the electorate. 


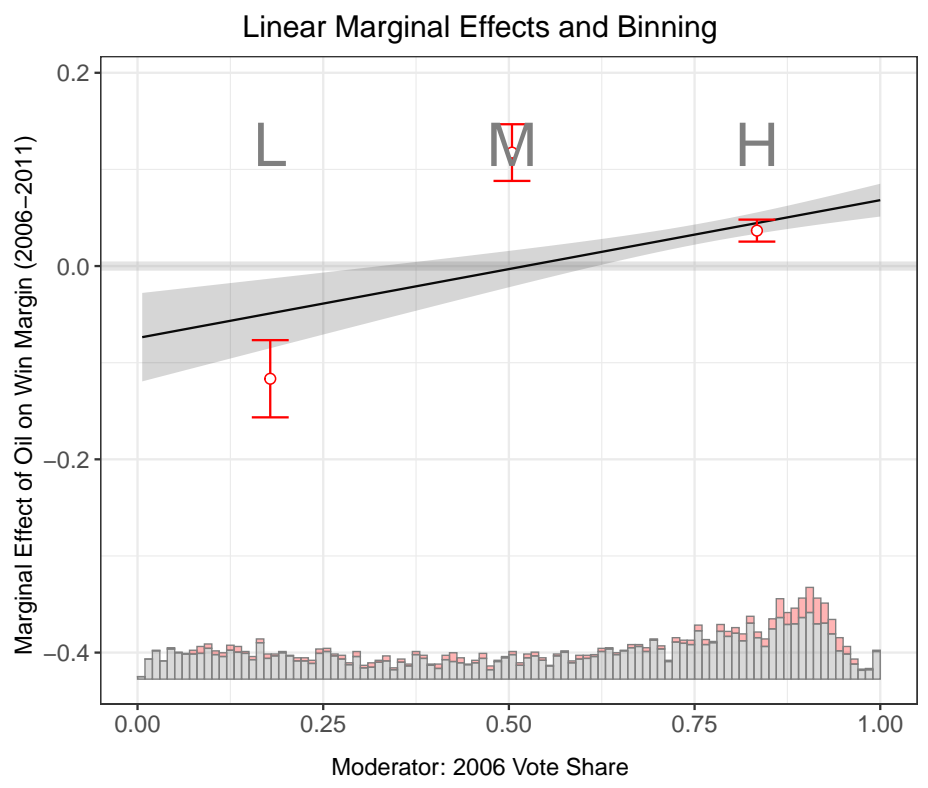

(a) Binning Estimator

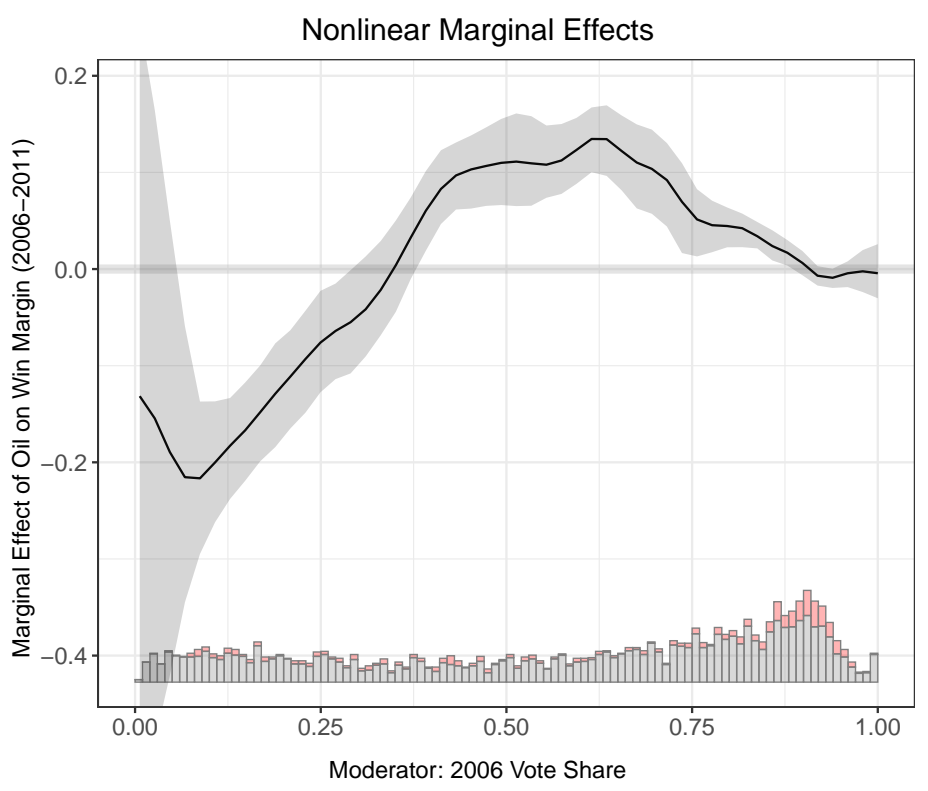

(b) Kernel Estimator

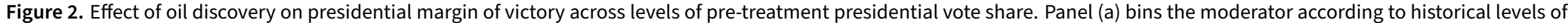

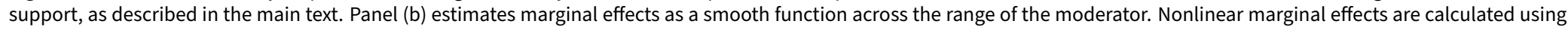
kernel density estimation. 


\section{Conclusion}

Research on the relationship between oil wealth and political outcomes remains centrally concerned with understanding why oil production strengthens incumbents in some contexts and weakens them in others through unrest, violence, and the emergence of credible challengers. We show that while oil discoveries caused a modest average increase in electoral support for the chief executive in Uganda, Museveni experienced the biggest gains in localities that had only moderately supported him in the past. Our evidence suggests that these results are due not to increases in actual spending or electoral intimidation but rather to the way in which oil discoveries shape the electoral and distributive bargains between voters and the incumbent. Ultimately, these findings highlight the importance of the pre-production period, showing that oil discoveries can strengthen incumbency advantage in precisely those locations that historically were more competitive and, moreover, that these dynamics arise (and could become entrenched) long before revenues start to flow.

While our results come from the single case, we expect them to generalize broadly to other authoritarian regimes holding periodic elections (see the discussion in Appendix M). As such, they should motivate future research into how oil discoveries shape the distributive and electoral bargains between voters and incumbents and, moreover, how these bargains vary depending on whether discoveries occur in core, competitive, or opposition regions. While research on the conflict curse has long acknowledged the importance of subnational variation-focusing on the consequences for unrest and violence when oil is discovered in opposition (or marginalized) localities (Asal et al. 2016; Hunziker and Cederman 2017)—surprisingly few political resource curse studies have examined how historical incumbent support shapes the electoral consequences of oil subnationally. Our study highlights the value of using a single moderating factor like historical support to bridge these literatures. While our findings emerge from exploratory analysis and we seek to avoid post-hoc hypothesis-testing, our results call for more attention to how historical incumbent support shapes the subnational distributive politics of oil, with important implications for understanding when and how both the political and conflict resource curses might emerge.

More generally, our results highlight the need for further attention to the pre-production period because longer-run outcomes could be driven by pre- versus post-production differences in support. Raised expectations in the pre-production period might set the stage for even more incumbent support if those expectations are realized or for subsequent disappointment if those expectations are 
thwarted. Understanding how expectations and support change across pre- and post-production periods might offer new insights into incumbency advantage highlighted in the political resource curse literature or into the underlying roots of deep-seated grievances highlighted in conflict curse literature.

\section{References}

Ahmad, Ehtisham, and Eric Mottu. 2003. Fiscal policy formulation and implementation in oil-producing countries. Chap. Oil Revenue Assignments: Country Experiences and Issues, edited by J.M Davis, R. Ossowski, and A. Fedelino. International Monetary Fund.

Arezki, Rabah, Valerie A Ramey, and Liugang Sheng. 2017. News shocks in open economies: evidence from giant oil discoveries. The quarterly journal of economics 132 (1): 103-155.

Asal, Victor, Michael Findley, James Piazza, and James Walsh. 2016. Political exclusion, oil, and ethnic armed conflict. Journal of Conflict Resolution 60 (8): 1343-1367.

Aslaksen, Silje. 2010. Oil as sand in the democratic machine? Journal of Peace Research 47 (4): 421-431.

Bashir, Twesigye, and Kathleen Brophy. 2015. Up against giants: oil-influenced land injustices in the albertine graben in uganda. Civic Response on Environment and Development Case Studies).

Beblawi, Hazem, and Giacomo Luciani. 1987. The rentier state. London: Croom Helm.

Bhattacharyya, Sambit, Louis Conradie, and Rabah Arezki. 2017. Resource discovery and the politics of fiscal decentralization. Journal of Comparative Economics 45 (2): 366-382.

Brock, Joe. 2010. Tullow oil to exit uganda tax dispute. Reuters September 15. https://www.reuters.com/article/tullowuganda-idAFLDE68E26S20100915.

Caselli, Francesco, and Tom Cunningham. 2009. Leader behavior and the natural resource curse. Oxford Economic Papers 61:628-650.

Cust, James, and Justice Tei Mensah. 2020. Natural resource discoveries, citizen expectations and household decisions. The World Bank.

Dal Bo, Ernesto, and Robert Powell. 2009. A model of spoils politics. American Journal of Political Science 53 (1): 207-222.

Frynas, Jedrzej George, and Lars Buur. 2020. The presource curse in africa: economic and political effects of anticipating natural resource revenues. The Extractive Industries and Society 7 (4): 1257-1270.

Golden, Miriam, and Brian Min. 2013. Distributive politics around the world. Annual Review of Political Science 16 (73): 73-99.

Gottlieb, Jessica, Guy Grossman, Horacio Larreguy, and Benjamin Marx. 2019. A signaling theory of distributive policy choice: evidence from senegal. The Journal of Politics 81 (2): 631-647. 
Hainmueller, Jens, Jonathan Mummolo, and Yiqing Xu. 2019. How much should we trust estimates from multiplicative interaction models? simple tools to improve empirical practice. Political Analysis 27 (2): 163-192.

Harding, Torfinn, Radoslaw Stefanski, and Gerhard Toews. 2020. Boom goes the price: giant resource discoveries and real exchange rate appreciation. The Economic Journal 130 (630): 1715-1728.

Hunziker, Philipp, and Lars-Erik Cederman. 2017. No extraction without representation: the ethno-regional oil curse and secessionist conflict. Journal of Peace Research 54, no. 3 (March): 365-381. https://doi.org/10.1177/0022343316687365.

Khan, Tehmina S, Trang Thi Thuy Nguyen, Richard Schodde, and Franziska Ohnsorge. 2016. From commodity discovery to production. World Bank Policy Research Working Paper, no. 7823.

Kiiza, Julius, Lawrence Bategeka, and Sarah Ssewanyana. 2011. Righting resource curse wrongs in uganda: the case of oil discovery and the management of popular expectations. Economic Policy Research Centre (July).

Langer, Arnim, Ukoha Ukiwo, and Pamela Mbabazi. 2019. Oil wealth and development in uganda and beyond: prospects, opportunities, and challenges. Leuven University Press.

Lee, Bryan, and Kendra Dupuy. 2018. Understanding the lie of the land: an institutional analysis of petro-governance in tanzania. Journal of Energy \& Natural Resources Law 36 (1): 85-101.

Lei, Yu-Hsiang, and Guy Michaels. 2014. Do giant oilfield discoveries fuel internal armed conflicts? Journal of Development Economics 110:139-157.

Lyatuu, Justus. 2018. Museveni to masaka: vote wisely to get roads. The Observer December 10. https://web.archive.org/web/ 20181210142459/https://observer.ug/news/headlines/59439-museveni-to-masaka-vote-wisely-to-have-roads.

Mahdavi, Paasha. 2015. Explaining the Oil Advantage: Effects of Natural Resource Wealth on Incumbent Reelection in Iran. World Politics 67 (2): 226-267.

McClure, Charles. 2003. Fiscal policy formulation and implementation in oil-producing countries. Chap. The Assignment of Oil Tax Revenue, edited by J.M Davis, R. Ossowski, and A. Fedelino. International Monetary Fund.

Menaldo, Victor. 2016. The institutions curse: natural resources, politics, and development. Cambridge University Press.

Mihalyi, David, and Thomas Scurfield. 2020. How did africa's prospective petroleum producers fall victim to the presource curse?

Nimmagadda, Shastri Lakshman, Reuben Kashambuzi, Ernest Rubondo, and Robert Kasande. 2006. Application of integrated geophysical strategies in the albertine graben and its petroleum potentiality. AAPG International Conference and Exhibition.

Omgba, Luc Désiré. 2009. On the duration of political power in africa: the role of oil rents. Comparative Political Studies 42 (3): 416-436.

Paine, Jack. 2019. Strategic civil war aims and the resource curse. Working paper.

Robinson, James, Ragner Torvik, and Thierry Verdier. 2006. Political foundations of the resource curse. Journal of Development Economics 79:447-468. 
Ross, Michael. 2012. The Oil Curse: How Petroleum Wealth Shapes the Development of Nations. Princeton University Press.

Stokes, Susan, Thad Dunning, Marcelo Nazareno, and Valeria Brusco. 2013. Brokers, voters, and clientelism. Cambridge University Press.

Tripp, Aili Mari. 2010. Museveni's uganda: paradoxes of power in a hybrid regime. Vol. 6. Lynne Rienner Publishers Boulder, CO.

World Bank. 2020. Uganda oil revenue management: closing gaps in the fiscal and savings frameworks to maximize benefits. World Bank.

Zhang, Gongcheng, Hongjun Qu, Guojun Chen, Chong Zhao, Fenglian Zhang, Haizhang Yang, Zhao Zhao, and Ming Ma. 2019. Giant discoveries of oil and gas fields in global deepwaters in the past 40 years and the prospect of exploration. Journal of Natural Gas Geoscience 4 (1): 1-28. 